\title{
Implementação da política de inclusão financeira no Brasil: interações entre cooperativas de crédito e atores governamentais
}

\author{
Implementation of the financial inclusion policy in Brazil: interactions of credit \\ cooperatives
}

\begin{abstract}
Resumo
O presente artigo tem por objetivo compreender como são estabelecidas as interações entre as cooperativas de crédito, enquanto atores não estatais atuando no processo de implementação da Política de Inclusão Financeira, e os atores estatais, coordenadores dessa política pública. A metodologia se guiou pelos procedimentos da pesquisa qualitativa, com levantamento de dados primários, sendo realizadas entrevistas semiestruturadas com cooperativas de crédito (atores implementadores) e órgãos governamentais (atores coordenadores). Os dados foram analisados por meio da análise de conteúdo. A pesquisa revelou que as cooperativas de crédito envolvidas influenciam de forma efetiva não apenas a implementação, mas também a formulação da política para a inclusão financeira e que as interações mantidas entre elas e os coordenadores da política, principalmente o Banco Central do Brasil (BCB), são fortes e ocorrem num processo de cooperação, com objetivos e interesses comuns de promover a adequada inclusão financeira da população brasileira.
\end{abstract}

Palavras-Chave: implementação de política pública. inclusão financeira, atores. interações.

\begin{abstract}
This article aims to understand how interactions are established between credit cooperatives, as non-state actors acting in the process of implementation of the Financial Inclusion Policy, and state actors, coordinators of this public policy. The methodology was guided by the qualitative research procedures, with primary data survey, and semi-structured interviews were conducted with credit unions (implementing actors) and government agencies (coordinating actors). Data were analyzed through content analysis. The survey revealed that the credit cooperatives involved effectively influence not only the implementation but also the formulation of the policy for financial inclusion and the interactions between them and the policy coordinators, especially the Central Bank of Brazil (BCB)., are strong and occur in a process of cooperation, with common goals and interests of promoting the proper financial inclusion of the Brazilian population.
\end{abstract}

Keywords: public policy implementation. financial inclusion, actors, interactions.

Lauro Emilio Gonzalez Farias ${ }^{\text {I, }}$ Ligia Greatti ${ }^{\text {II }}$.

${ }^{\text {I } U n i v e r s i d a d e ~ E s t a d u a l ~ d e ~ M a r i n g a ́ . ~ M a r i n g a ́, ~ P R . ~ L a u r o . G o n z a l e z @ f g v . b r ~}$

${ }^{\text {II } U n i v e r s i d a d e ~ E s t a d u a l ~ d e ~ M a r i n g a ́ . ~ M a r i n g a ́, ~ P R . ~ g r e a t t i @ u e m . b r ~}$ 


\section{Introdução}

Uma política pública se constitui como um conjunto de ações e intervenções, do Estado e da sociedade, na tentativa de solucionar problemas considerados públicos. Um tema de destacada importância no debate sobre políticas públicas, nos últimos anos, é a questão da exclusão financeira comoum problema social e econômico de grande abrangência. Buscando minimizar esse problema, o processo de inclusão financeira vem sendo discutido como um conjunto de ações voltado para a prestação de serviços financeiros adequados e sustentáveis para a população de baixa renda, tradicionalmente excluída do sistema financeiro tradicional, com a utilização de produtos, processos e gestão diferenciados. Na prática, significa permitir acesso a mecanismos financeiros que contribuam para a qualidade de vida, desenvolvimento humano e social (CACCIAMALI; CHAHAD; TATEI, 2008).

No Brasil, a inclusão financeira não é formalizada como uma política nacional, no entanto, existem diversas ações e programas instituídos neste âmbito, que visam inserir a camada mais pobre da população na utilização de serviços financeiros, como o projeto para bancarização, micro poupança, micro seguro, educação financeira, moedas sociais, Programa Cidadania Financeira (PCF), além do Programa Nacional do Microcrédito Produtivo Orientado (PNMPO), sendo este o projeto com maior impacto dentro do tema. Esse conjunto de ações e programas pode ser considerado uma Política de Inclusão Financeira, mesmo não existindo uma formalização como tal. Como em toda política pública, existe a presença dos atores implementadores, que são os responsáveis por fazer com que a política pública chegue até o seu público-alvo, e nesse caso são as Instituições de Microfinanças (IMFs), que atuam como canais de acesso, sendo constituídas na forma de Organizações Não-Governamentais (ONGs), Organizações da Sociedade Civil de Interesse Público (Oscips), Cooperativas de Crédito, Sociedades de Crédito ao Microempreendedor e à Empresa de Pequeno Porte (SCMEPPs), fundos públicos, além de bancos comerciais públicos e privados (SOARES; MELO SOBRINHO, 2008).

Dentre tais atores implementadores, as cooperativas de crédito são de singular importância, na medida em que captam recursos privados e promovem a sua aplicação na própria comunidade. Representam iniciativas dos próprios cidadãos, contribuindo de forma relevante para o desenvolvimento local, especialmente nos aspectos de formação de poupança e concessão de créditos destinados às atividades produtivas, que trazem benefícios em termos de geração de empregos e de distribuição de renda. Ofertam serviços financeiros mais adequados às necessidades locais e, assim, são consideradas um dos principais atores na implementação da Política de Inclusão Financeira, pelo volume de serviços ofertados e pela alta capilaridade, sendo, por estes motivos, o foco deste trabalho.

Além disso, as cooperativas de crédito representam uma modalidade de atores diferenciada, (não estatais), participando das políticas públicas. Atualmente, a concepção de uma política pública não envolve apenas a presença de atores governamentais, envolve também a atuação de outros atores, tanto na sua formulação quanto na execução e implementação. Nesse sentido, esse trabalho tem como finalidade compreender como são estabelecidas as interações entre as cooperativas de crédito, enquanto atores não estatais atuando no processo de implementação da Política de Inclusão Financeira, e os atores estatais, coordenadores dessa política pública. Para alcançar o objetivo da pesquisa, foi escolhido o modelo de análise proposto por Subirats et al. (2012) por ser um modelo que apresenta as categorias que mais se aproximam daquelas que este estudo julga importantes de serem analisadas. Considera que as relações entre os atores são influenciadas pelo conteúdo da política, pelo conjunto de valores, ideias e interesses dos atores, pelos recursos que mobilizam e negociam, e, pelas regras e normas institucionais que os envolvem na política.

Tal estudo se justifica pelo fato de que estudos sobre esse tipo de interação, estabelecida entre atores estatais e não estatais, não é comum na área de políticas públicas, uma vez que na maioria delas os atores implementadores fazem parte da própria burocracia estatal. Assim, as 
contribuições que esta pesquisa poderá trazer estão relacionadas ao olhar para a implementação como um processo de interação entre o público e o privado. Portanto, traz como pressuposto que a implementação de uma política não é apenas uma prática executada pelos agentes de implementação de forma operacional, mas sim um processo complexo e dinâmico norteado por interações que se estabelecem entre os atores envolvidos. Para atingir os objetivos, este trabalho foi dividido em quatro seções, além desta introdução. A seção 2 traz uma conceituação sobre políticas públicas, bem como sobre as relações dos atores na fase de implementação. A seção 3 traz uma descrição sobre o modelo teórico de análise e sobre os procedimentos metodológicos utilizados. Já na seção 4 consta a análise da pesquisa, realizada com base no modelo de Subirats et al (2012), a partir das entrevistas com atores do setor cooperativista e atores governamentais. Por fim, estão as Considerações Finais do estudo seguidas das Referências utilizadas no decorrer do trabalho.

\section{O Processo de Implementação de política pública}

Esta seção propõe, no primeiro momento, conceituar políticas públicas e discorrer sobre suas etapas, tendo como intuito traçar uma sequência que leve ao processo de implementação. No segundo momento, busca discutir sobre a análise da implementação com base nas interações entre os atores envolvidos nessa etapa. No terceiro momento, expõe a Política de Inclusão Financeira, relatando como ela se desenvolveu e quem são os principais atores envolvidos.

\subsection{Política pública: processo e análise}

Uma política pública, em um aspecto global, está situada em torno de uma situaçãoproblema ou problema público, para o qual se busca uma solução (PROCOPIUCK, 2013). Com o foco na solução de um problema público, a perspectiva de política pública vai além da perspectiva de políticas governamentais, na medida em que o governo, com sua estrutura administrativa, não é a única instituição a servir à comunidade, isto é, a promover "políticas públicas" (HEIDEMANN, 2010). Dentro dessa perspectiva, Secchi (2014) coloca a existência de duas abordagens no estabelecimento de políticas públicas. A abordagem estatista, que as considera como monopólio de atores estatais, e a abordagem multicêntrica, que considera a atuação de outras organizações, juntamente com os atores estatais, como protagonistas no estabelecimento das políticas públicas, como organizações privadas, organizações não governamentais, organismos multilaterais, redes. Nesse mesmo sentido, marcando a presença de atores não estatais, Subirats et al. (2012) definem a política pública como um conjunto encadeado de decisões e de ações, resultado das interações estruturadas entre diferentes atores, públicos e privados, que, por diversas razões, estão envolvidos no surgimento, na formulação e na resolução de um problema politicamente definido como público. Knoepfel et al. (2007) contribuem no mesmo sentido, colocando que uma política pública é definida como um conjunto de decisões ou ações intencionalmente coerentes, tomadas por diferentes atores, públicos e ocasionalmente privados, cujos recursos, ligações institucionais e interesses variam para resolver de forma pontual um problema politicamente definido como coletivo. Tais autores consideram como sendo um conjunto de decisões e ações resultantes das interações constantes entre atores públicos e privados cuja conduta é influenciada pelos recursos disponíveis e por regras institucionais gerais e específicas pertencentes a cada política.

Um dos meios mais utilizados para fins analíticos é olhar para a política pública como um processo, ou seja, como um conjunto de etapas ou fases por meio das quais a solução de um problema público flui de uma forma mais ou menos sequencial, formando um ciclo. As fases mais comumente destacadas no ciclo de políticas públicas, relacionados por diferentes autores podem ser definidas como: identificação de um problema; definição da agenda (quando são decididos os assuntos que serão trazidos e debatidos na esfera pública) (KINGDON, 2006); formulação (quando são especificadas as alternativas e elaborados os planos de ação) (SOUZA, 2006); implementação (quando as políticas são colocadas em prática) (HILL, 2006); e avaliação (quando são verificados os resultados das políticas implementadas) (VIANA, 1996). A distinção de cada fase é vista como apropriada para fins de estudos, pois cada uma delas envolve diferentes tipos de atores, negociações, 
decisões e, portanto, diferentes ênfases de análise, embora, na prática, as fases ou etapas se sobrepõem num processo dinâmico e interativo.

Este trabalho teve como foco de análise a fase da implementação, que é vista como um processo no qual as intenções, construídas na fase de formulação da política, são convertidas em ações, ou seja, um processo que busca a realização concreta dos objetivos para produzir do mesmo modo determinados resultados, impactos e consequências (VIANA, 1996; FREY, 2000; AZEREDO, LUIZA; BAPTISTA, 2014). A implementação quase nunca está a cargo de apenas um ator e nem sempre ocorre apenas no âmbito de uma organização, mas de um campo interorganizacional no qual há a participação de organizações públicas e privadas.

Cada vez de forma mais frequente atores privados vêm atuando na implementação de políticas públicas e existem poucos estudos que exploram a existência dessa modalidade de agentes implementadores, pois muitos adotam como foco de análise apenas o ator governamental, principalmente o burocrata de nível de rua, atuando na implementação. Este estudo se enquadra nessa abordagem e vai de encontro ao que Souza (2003) coloca sobre os estudos mais recentes, que têm como foco de análise compreender a implementação como um processo de interação e negociação entre diferentes atores, públicos e privados, envolvidos na prestação dos serviços, considerando cada qual com seus interesses específicos, objetivos, estratégias, atividades e informações, pois os resultados da política estão diretamente vinculados a esses fatores. Portanto, o tópico a seguir traz a visão de alguns autores que adotam essa perspectiva de análise.

\subsection{Análise da implementação de políticas públicas com base nas interações entre os atores}

Conforme colocado por Souza (2003), é preciso superar o que a literatura chama de primeira geração de estudos nessa fase de implementação de políticas públicas, excessivamente concentrada nos fracassos, pouco preocupada com as questões políticas e fortemente assentada no pressuposto de que a formulação e a implementação de políticas públicas são processos exclusivamente racionais e lineares, desvinculados do processo político. Coloca que é preciso avançar para a chamada segunda geração, que deve seguir na direção do desenvolvimento de tipologias analíticas, e concentrar esforços no sentido de identificar outras diferentes variáveis que influenciam e que causam impactos sobre os resultados das políticas públicas.

A implementação deve ser vista como um longo e complexo processo com diversos pontos de decisão, envolvendo atores com valores que competem entre si, com interesses conflitantes e com diferenças de poder. Segundo Hill (2006), uma abordagem que realiza a análise da implementação, de forma mais realista, precisa atentar para os fatos de que:

- a implementação envolve complexas interações intra-organizacionais;

- a análise dessas interações deve nos levar a questões sobre negociação entre atores que são quase autônomos;

- essa autonomia pode estar vinculada a reivindicações de legitimidade que enfatizam a recalcitrância, as deficiências e os déficits;

- essas complexidades precisam ser vistas como contidas dentro de diferentes sistemas de políticas nacionais ou transnacionais que influenciam os jogos realizados e as legitimidades reclamadas. (HILL, 2006, p. 85).

Uma abordagem ao estudo da implementação se concentra sobre os atores e as instituições em si e suas interações, conforme contribuem Knoepfel et al. (2007) ao colocar que o "jogo" dos atores não depende apenas de seus respectivos interesses, mas também de recursos (direito, pessoal, dinheiro, informação, tempo, consenso, organização, infraestrutura, força, apoio político) que conseguem explorar para defender suas posições, bem como das regras institucionais que marcam a 
política. Rocha (2012) acrescenta que uma proposta de análise de implementação a ser explorada, é a desenvolvida por Hjern e Porter (1993 apud ROCHA, 2012), que considera uma nova unidade administrativa para análise, o conjunto de atores privados e públicos envolvidos, pois cada vez mais atores privados vêm atuando na implementação de políticas públicas e apenas estudos mais recentes vêm explorando a existência dessa modalidade de agentes implementadores. Os autores colocam que os atores e organizações nas estruturas de implementação possuem uma variedade de objetivos e motivações, e cada um decide participar dessa estrutura por suas próprias razões. Assim a intensidade do interesse no programa em questão varia substancialmente de um ator para outro.

Neste sentido, Secchi (2014, p.57) coloca que "os elementos básicos de qualquer análise sobre o processo de implementação são pessoas e organizações, com interesses, competências (técnicas, humanas, de gestão) e comportamentos variados". Assim como, também fazem parte desses elementos analíticos as relações existentes entre as pessoas e entre organizações, as instituições vigentes (regras formais e informais), os recursos financeiros que disponibilizam, os materiais e procedimentos, informação e comunicação, elementos políticos (com sua capacidade de influência), entre outros (SECCHI, 2014). Os problemas de implementação, neste sentido, estão relacionados com a diversidade de organizações e atores envolvidos, sendo a interação e relação entre eles, atores formuladores e implementadores, um ponto de extrema importância nesse contexto e, portanto, um elemento essencial de análise. Quanto aos formuladores, é necessário que compreendam como ocorre o processo de implementação e em que condições acontece, para então saber o que esperar enquanto resultados. Quanto aos implementadores, é necessária uma plena compreensão da política, da sua natureza e objetivos, e dos problemas a serem enfrentados, para haver então uma resposta de aceitação e comprometimento com os resultados. Ou seja, ambos precisam ter conhecimento pleno do processo da política como um todo, desde a identificação do problema até os resultados esperados enquanto solução dos mesmos, para que assim consigam estabelecer um processo de interação e relação condizentes com a política.

Muitos autores, como os citados até então, mencionam a importância da análise da implementação baseada nas interações ou relações. Nesse mesmo sentido, Subirats et al. (2012) destacam e pontuam os elementos essenciais de análise em qualquer das fases de uma política pública, inclusive da implementação. Além do conteúdo da política, apontam que é necessário levar em consideração os valores, ideias e interesses dos atores, os recursos necessários para a execução da política e as regras institucionais que envolvem a política, pois esses aspectos são elementos-chaves de análise para qualquer fenômeno a ser estudado. De acordo com os autores, o processo de interação entre atores são influenciados por esses quatro elementos de análise. Neste mesmo sentido, Kiviniemi (1985 apud VIANA, 1996) afirma que a implementação é definida no processo em que a política governamental envolve-se com sujeitos não-governamentais, de tal modo que em cada momento interagem, com ideias, recursos e ações próprios. As interações podem ocorrer de forma mais forte ou mais fraca, pois cada ator envolvido possui suas intenções próprias, ocorrendo então o encontro de várias e diversas intenções na implementação da política pública, assim como acontece com as ideias e também com os recursos de cada um. Assim, se as ideias e os valores desses atores nortearem a favor da política e se os recursos que mobilizam forem fortes, as ações desenvolvidas por eles serão no sentido de cooperação com a política em questão.

Essas abordagens contribuem para mostrar que outros fatores também podem influenciar o sucesso ou fracasso na implementação de uma política pública, como: o nível de conflito ou de consenso sobre o problema a ser atingido, a clareza dos objetivos e da natureza da política, o tempo necessário para a implementação, as ideias, valores e interesses dos atores, os recursos políticos e econômicos envolvidos, o apoio contínuo do aparato administrativo com sua capacidade e experiência, as regras que regulamentam e norteiam a política. Em um processo de interação, entram no contexto variadas ideias e valores, interesses, demandas e necessidades, normas institucionais e constrangimentos, recursos, que devem ser negociados para que haja uma coordenação e alinhamento na construção das práticas de implementação. 


\subsection{A Política de Inclusão Financeira e seus atores}

As discussões sobre inclusão financeira se iniciaram no Brasil a partir de 1995, com a criação do Conselho da Comunidade Solidária e se estendeu para seminários sobre o microcrédito em $2002 \mathrm{e}$ para microfinanças, em 2003. A partir de 2009 o BCB realizou fóruns anuais com o tema de inclusão financeira, envolvendo outras instituições financeiras, por meio dos quais foram realizados diagnósticos sobre a inclusão financeira no Brasil com publicação de relatórios anuais. Houve lançamento de livros e a entrada do Brasil para participação do debate internacional, no âmbito do G-20. Em 2011, o BCB lançou a Parceria Nacional para Inclusão Financeira (PNIF), sendo uma rede de atores públicos e privados engajados em ações coordenadas para a promoção da adequada inclusão financeira da população brasileira (BCB, 2012). Em 2012 publicou o Plano de Ação para Fortalecimento do Ambiente Institucional priorizando três linhas de ação (diagnóstico, regulação, educação e transparência), cujos resultados foram mostrados nos fóruns de 2012 a 2014. Também foi criado nesse período o Índice de Inclusão Financeira e, em 2015, foi apresentado um relatório da evolução da inclusão financeira no Brasil de 2010 a 2014, considerando o acesso, o uso e a qualidade. A partir de 2015, o fórum passou a ser sobre a temática Cidadania Financeira, sendo o último realizado em novembro de 2018 (BCB, 2009; 2010; 2012; 2018).

A inclusão financeira refere-se ao acesso e uso de serviços financeiros formais adequados e que satisfaçam as necessidades da população, principalmente a de baixa renda. Produtos apropriados que atendam às necessidades dos clientes são sustentáveis tanto para provedores quanto para usuários, mas que não envolvam preços abusivos é um aspecto importante quando se trata de incluir financeiramente a população (BECK, 2015). Promover a inclusão financeira é uma medida que disponibiliza e facilita o acesso ao sistema financeiro por pessoas de baixa renda ou que vivem em locais onde não há instituição financeira instalada. É o estado em que todos os adultos, independente da classe social ou do local onde moram, têm acesso efetivo aos seguintes serviços financeiros providos por instituições formais: crédito, poupança, pagamentos, seguros, previdência e investimentos $(\mathrm{BCB}, 2018)$. É considerada como processo de adequação dos serviços financeiros às necessidades da população, de forma que possa contribuir com sua qualidade de vida, seu desenvolvimento social e econômico.

A ampliação e melhoria do acesso da população a serviços financeiros têm sido trabalhadas pelo BCB nos fóruns que promove, tanto que, segundo Andrade e Diniz (2016), foi apontado como a instituição mais apropriada para promover o diálogo entre reguladores, operadores e fomentadores atores relevantes do processo de inclusão financeira. Segundo os autores, os eventos, reuniões e grupos de trabalho que o $\mathrm{BCB}$ organizou são exemplos de iniciativas para a articulação e coordenação de atores. Por essas ações, o BCB é considerado como ator coordenador da política de inclusão financeira no Brasil, atuando no nível macro, conforme a classificação de Helms (2006), na qual os atores de políticas públicas são classificados em três níveis de atuação (macro, meso e micro), sendo o nível macro composto pelos atores responsáveis pela estrutura regulatória e é o âmbito no qual ocorrem as formulações de políticas públicas. Fazem parte deste nível, além do BCB, os ministérios e outros órgãos governamentais envolvidos na política de inclusão financeira. $\mathrm{O} B C B$ adota um papel fundamental para as diretrizes das políticas de inclusão financeira, por ser uma instituição que normatiza e regula o sistema financeiro e as instituições bancárias que o compõe. Como a inclusão financeira não é uma política formalizada e que não passou por um processo de formulação, pode-se considerar que o BCB atua na função de coordenador, direcionando as ações e programas em prol da inclusão financeira no Brasil.

O nível meso é formado por instituições ligadas à infraestrutura do sistema financeiro, responsáveis por soluções tecnológicas, logísticas, de risco, de apoio e provedor de capacitação, entre outras (HELMS, 2006). No Brasil, é possível citar a Central de Risco de Crédito do BCB, o Serasa e o SPC (Serviços de Proteção ao Crédito), como instituições que compartilham informação de crédito, e o SEBRAE (Serviço Brasileiro de Apoio às Micro e Pequenas Empresas), como instituição de apoio e treinamento. A atuação dessas instituições reduz custos de transação e promove transparência dos 
serviços. Já o nível micro é constituído por instituições que estão em contato direto com os clientes ou usuários (HELMS, 2006). No caso brasileiro fazem parte do nível micro as instituições de microfinanças (IMFs), como os bancos públicos e comerciais, as cooperativas de crédito (que é o foco deste estudo), as Sociedades de Crédito ao Microempreendedor e à Empresa de Pequeno Porte (SCMEPPs), as OSCIPs, as Organizações Não-Governamentais (ONGs) e os consórcios (SOARES; MELO SOBRINHO, 2008). Essas instituições são responsáveis por fazer com que os serviços financeiros cheguem ao alcance dos destinatários, e por isso são considerados atores implementadores da inclusão financeira. Assim, a consolidação da inclusão financeira no Brasil depende da integração desses diversos atores, governamentais e não governamentais, dedicados à prestação de serviços financeiros em condições acessíveis à população de baixa renda.

A tempo, cabe ressaltar a importância do cooperativismo de crédito para a inclusão financeira. Primeiro pelo oferecimento de um conjunto de produtos e serviços financeiros com qualidade e preços mais acessíveis, uma vez que atende ao interesse exclusivo de seus cooperados, sem visar o lucro. Segundo, pelo poder de se organizar em comunidades com pouquíssimo acesso a serviços financeiros, tais como as localizadas longe dos grandes centros, bem como comunidades de baixa renda que são pouco atrativas para o setor bancário tradicional. Terceiro, por sua capacidade de mobilizar e aplicar recursos, por meio de poupança e crédito, em benefício da própria comunidade, o que estimula pequenos empreendimentos, geradores de emprego e renda. Quarto, porque contribui para o aumento da competitividade do sistema financeiro, promovendo equalização das taxas de juros e a queda do spread bancário. E, finalmente, pelo incentivo à educação financeira que contribui para uma vida financeira saudável da comunidade e sustentável no longo prazo.

\section{Processos metodológicos}

Nessa seção é exposto tanto o modelo teórico com os elementos que guiam a análise, como os métodos utilizados para a coleta de dados.

\subsection{Modelo teórico}

A análise dessa pesquisa olha para a implementação da política de inclusão financeira como um processo dinâmico, que procura analisar como as relações se estabelecem entre as cooperativas de crédito, enquanto agente implementador, e o $\mathrm{BCB}$, enquanto ator governamental coordenador da política, além de outros órgãos envolvidos diretamente. A abordagem de análise está baseada nos elementos elencados por Subirats et al. (2012), para uma análise da implementação de uma política pública sendo eles o conteúdo da política, os atores e suas condutas, os recursos que mobilizam e as regras institucionais estabelecidas.

Figura o1: Os elementos de Análise

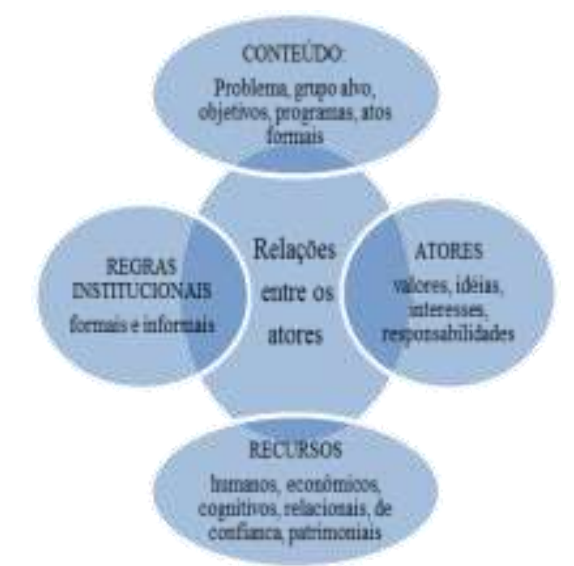

Fonte: Adaptado de SUBIRATS et al. (2012). 
Tem-se como pressuposto que os atores envolvidos em uma política pública, com seu conjunto de valores, ideias e interesses, a partir dos recursos que mobilizam e negociam, seguindo as regras e normas institucionais que os envolvem na política (tanto gerais, aplicáveis a todas as políticas públicas, quanto as específicas, próprias de uma política em questão), levando em consideração o conteúdo da política na qual estão atuando, são aspectos que norteiam as interações entre os atores.

Esse modelo foi utilizado por considerar a existência de atores estatais e paraestatais atuando na implementação das políticas públicas, indo ao encontro da finalidade desse estudo, justamente por tentar entender como atores paraestatais ou de mercado, no caso dessa pesquisa as cooperativas de crédito, pautam suas relações com atores governamentais que coordenam a política, no caso dessa pesquisa o BCB. Embora o modelo seja recente, de 2012, outros trabalhos sobre implementação de políticas públicas já foram desenvolvidos utilizando-o como base, como o de Craveiro (2015) e Abreu (2014).

\subsection{Coleta de dados}

Esta pesquisa dá ênfase às instituições e às interações estabelecidas entre elas, sendo, portanto, considerada como pesquisa qualitativa, que, segundo Van Maanen (1979) procura analisar o sentido de determinados fenômenos que ocorrem naturalmente no mundo social. Nas pesquisas qualitativas, o objeto não é um dado inerte e neutro, mas está possuído de significados e relações que sujeitos concretos criam em suas ações (GIL, 2008). Como objetos de estudo foram selecionados para a pesquisa dois grupos de atores, escolhidos de forma proposital, por haver alta probabilidade de se encontrar o que se deseja investigar. O primeiro grupo foi composto por três sistemas de cooperativas de crédito brasileiras, o Sicredi, o Sicoob e a Cresol, enquanto instituições financeiras não governamentais, participando da implementação da política pública, bem como a OCB (Organização das Cooperativas do Brasil). O segundo grupo foi composto pelo $\mathrm{BCB}$, enquanto ator governamental coordenador da política, e também pelo Banco Nacional de Desenvolvimento Social (BNDES), o Ministério do Trabalho e Previdência Social (MTPS), o Ministério da Fazenda (MF), a Secretaria Especial de Agricultura Familiar e Desenvolvimento Agrário (Sead), por serem atores governamentais, citados pelos entrevistados do setor cooperativista de crédito, como sendo atores com os quais também se relacionam perante a política de inclusão financeira.

Uma pesquisa qualitativa pode utilizar-se de análise de discurso, de narrativa e outras técnicas para analisar os dados que são coletados por meio de entrevistas, observação, questionários, entre outros métodos. Assim, o instrumento utilizado para coleta de dados foi entrevistas semiestruturadas, realizadas no período de setembro a dezembro de 2016. Das 23 entrevistas realizadas, duas foram feitas presencialmente ( $\mathrm{AC}_{1} \mathrm{~b}$ e $\mathrm{AC} 2 \mathrm{a}$ ), uma foi feita via skype (AGij), uma foi respondida por escrito em arquivo Word, via e-mail $\left(\mathrm{AC}_{4}\right)$ e as demais foram feitas por telefone. A relação dos entrevistados se encontra na figura que segue. 
Figura 02: Atores Entrevistados na Pesquisa

\begin{tabular}{|c|c|c|c|}
\hline \multicolumn{4}{|c|}{ ATORES IMPLEMENTADORES (COOPERATIVISTAS - AC) } \\
\hline AC1a & Presidente Sicredi Confederação & $\mathrm{AC}_{3} \mathrm{a}$ & Diretor do Instituto Infocos Cresol \\
\hline $\mathrm{AC} 1 \mathrm{~b}$ & $\begin{array}{l}\text { Presidente Sicredi Central } \\
\text { Maringa/PR }\end{array}$ & $\mathrm{AC}_{3} \mathrm{~b}$ & $\begin{array}{c}\text { Presidente Central Cresol Sicoper - Porto } \\
\text { Alegre/RS }\end{array}$ \\
\hline $\mathrm{AC} 2 \mathrm{a}$ & $\begin{array}{l}\text { Presidente Central Sicoob } \\
\text { Maringa/PR }\end{array}$ & $\mathrm{AC}_{3 \mathrm{C}}$ & $\begin{array}{c}\text { Presidente Central Cresol Baser - Francisco } \\
\text { Beltrão/PR }\end{array}$ \\
\hline $\mathrm{AC}_{2} \mathrm{~b}$ & $\begin{array}{l}\text { Diretor da Área de Planejamento e } \\
\text { Assessor do Presidente do Sicoob } \\
\text { Confederação }\end{array}$ & $\mathrm{AC}_{4}$ & $\begin{array}{l}\text { Presidente Organização das Cooperativas } \\
\text { do Brasil (OCB) }\end{array}$ \\
\hline \multicolumn{4}{|c|}{ ATORES COORDENADORES (GOVERNAMENTAIS - AG) } \\
\hline AGia & \multicolumn{3}{|c|}{ BCB - Diretor de Administração (DIRAD) } \\
\hline AGıb & \multicolumn{3}{|c|}{ BCB - Chefe do Departamento de Educação Financeira (DEPEF) } \\
\hline AGic & \multicolumn{3}{|c|}{$\begin{array}{c}\text { BCB - Analista do Departamento de Organização do Sistema Financeiro (DEORF } \\
\text { Curitiba/PR) }\end{array}$} \\
\hline AGid & \multicolumn{3}{|c|}{$\begin{array}{c}\text { BCB - Gerente-Técnico do Departamento de Organização do Sistema Financeiro (DEORF - } \\
\text { Curitiba/PR) }\end{array}$} \\
\hline AGie & \multicolumn{3}{|c|}{$\begin{array}{c}\text { BCB - Gerente-Técnico do Departamento de Organização do Sistema Financeiro (DEORF } \\
\text { Belo Horizonte/MG) }\end{array}$} \\
\hline AGif & \multicolumn{3}{|c|}{$\begin{array}{c}\text { BCB - Gerente-Técnica do Departamento de Organização do Sistema Financeiro (DEORF em } \\
\text { Salvador/BA) }\end{array}$} \\
\hline AG1g & \multicolumn{3}{|c|}{$\begin{array}{c}\text { BCB - Chefe do Departamento de Regulação, Supervisão e Controle das Operações do } \\
\text { Crédito Rural e do Proagro (DEROP) }\end{array}$} \\
\hline AGih & \multicolumn{3}{|c|}{ BCB - Chefe-Adjunta do Departamento de Regulação do Sistema Financeiro (DENOR) } \\
\hline AGii & \multicolumn{3}{|c|}{$\begin{array}{l}\text { BCB - Chefe do Departamento de Supervisão de Cooperativas e de Instituições Não Bancárias } \\
\text { (DESUC) }\end{array}$} \\
\hline AGij & \multicolumn{3}{|c|}{ BCB - Chefe Aposentado do Departamento de Organização do Sistema Financeiro } \\
\hline $\mathrm{AG}_{2}$ & \multicolumn{3}{|c|}{$\begin{array}{c}\text { BNDES - Gerente do Departamento de Inclusão Produtiva- Área de Gestão Pública e } \\
\text { Socioambiental }\end{array}$} \\
\hline $\mathrm{AG}_{3}$ & \multicolumn{3}{|c|}{ MTPS - Coordenadora do PNMPO } \\
\hline $\mathrm{AG}_{4 a}$ & \multicolumn{3}{|c|}{ SEAD - Diretor Substituto do Departamento de Financiamento e Proteção da Produção } \\
\hline $\mathrm{AG}_{4} \mathrm{~b}$ & \multicolumn{3}{|c|}{$\begin{array}{c}\text { SEAD - Oficial Nacional da FAO e ex-secretário da Agricultura Familiar do Ministério do } \\
\text { Desenvolvimento Agrário }\end{array}$} \\
\hline $\mathrm{AG}_{5}$ & \multicolumn{3}{|c|}{ MF - Secretario Adjunto de Política Econômica (SPE) } \\
\hline
\end{tabular}

Fonte: elaborada pelos autores, 2018.

As entrevistas tiveram duração média de 1 (uma) hora, foram gravadas (com autorização dos entrevistados) e transcritas com o uso do Google Docs. O método qualitativo utilizado foi a análise de conteúdo das entrevistas, com auxílio do Software Atlas TI, de forma a realizar o estabelecimento das categorias e a codificação das entrevistas transcritas. Considerando as bases conceituais apresentadas nas primeiras seções e o modelo teórico exposto na presente seção, foram definidas as categorias de análise utilizadas para o tratamento do conteúdo das entrevistas realizadas.

\section{Discussões sobre as relações estabelecidas entre os atores governamentais e cooperativistas perante a política de inclusão financeira.}

Essa seção apresenta os resultados obtidos na pesquisa, no que diz respeito às relações estabelecidas entre os atores governamentais entrevistados, enquanto coordenadores da política de inclusão financeira, e os entrevistados das cooperativas de crédito, enquanto atores atuantes na implementação da política. As relações foram analisadas perante os elementos propostos por Subirats et al (2012), no intuito de verificar como se dão as relações em torno do (1) conteúdo da política, (2) dos valores, princípios e interesses dos atores, (3) dos recursos e (4) das regras. 


\subsection{Conteúdo da Política}

A política de inclusão financeira tem como foco a resposta para o enfrentamento de um problema reconhecido como público, assim como sugere Procopiuck (2013) e Heidemann (2010). Todos os entrevistados dessa pesquisa julgam a exclusão financeira de grande parte da população brasileira como uma realidade social inaceitável e, portanto, algo para ser enfrentado. Com relação ao conteúdo da política, existe entre os atores um consenso sobre o problema enfrentado, sobre o grupo-objetivo, e sobre sua importância, e isso faz com que haja um alinhamento de interesses e das responsabilidades que exercem na política, na tentativa de melhorar essa realidade. Essa relação entre os atores sobre o conteúdo da política dialoga com Kiviniemi (1985 apud Viana 1996) ao mencionar que quando existe conhecimento pleno do problema e dos resultados almejados enquanto solução dos mesmos, as interações dos atores são condizentes com a política.

No entanto, por não ser formalizada como política pública, a política de inclusão financeira não estabelece planos de ação e atos de implementação. Desta forma, mesmo tendo um conteúdo que é considerado importante pelos atores, a política ainda é vaga, voltada apenas à discussão e reflexão, sem a presença de uma forte coordenação e de ações mais incisivas, que realmente promovam a inclusão financeira. Isso mostra a necessidade dessa política ser desenhada como tal, e de incluir nesse desenho planos que efetivamente serão cumpridos em prol da inclusão financeira, ou seja, ir além da reflexão.

\subsection{Os Atores}

Os atores entrevistados, envolvidos na política de inclusão financeira, foram as cooperativas de crédito enquanto atores implementadores, o BCB enquanto ator coordenador e alguns ministérios e instituições envolvidas nesse processo, como o BNDES, o MTPS, a SEAD e o MF. As cooperativas de crédito entrevistadas estiveram presentes desde as primeiras discussões, sendo bastante ouvidas nos fóruns promovidos pelo $\mathrm{BCB}$, pelo fato de promoverem a inclusão financeira pelos seus próprios princípios, desde sua existência, e por fazer parte dos seus valores a promoção do desenvolvimento local. Elas são consideradas importantes para a inclusão financeira devido a sua capilaridade, ou seja, a capacidade de alcançar regiões onde os bancos comuns não têm interesse de atuar. Dois relatos, apresentados a seguir, demonstram que os atores governamentais possuem esse mesmo entendimento com relação às cooperativas de crédito.

(...) dentro dos sete princípios cooperativistas ela tem que se preocupar com a comunidade e para que ela tenha escala ela tem que cada vez mais buscar clientes e mais associados então a tendência dela é contribuir para uma grande inclusão financeira. (...) Inclusão é ter capilaridade e percebendo isso que o Banco Central começou a se dedicar bastante no seguimento de cooperativismo de crédito (...) $2 / 3$ do conjunto de instituições financeiras hoje é (sic) representado pela cooperativa de crédito (...) e se ela leva educação financeira ela faz o que é de melhor em termos de dar condições para a população usar de forma consciente. (AGra).

As cooperativas dobraram o número de cooperados nos últimos 5 anos, então elas estão realmente incluindo mais gente, elas estão fortemente preocupadas com a qualidade do que elas oferecem, com educação financeira, com fornecer informação para seu cooperando, com manter a cultura cooperativista aberta. (AGıb).

Como citado por $\mathrm{AG} 1 \mathrm{C}$, o BCB chegou à conclusão de que o tipo de instituição financeira que tem o interesse e a capacidade de atender municípios pequenos são as cooperativas de crédito, pois são instituições que não visam lucros, buscam associados e têm a capacidade de instalar postos de atendimentos. Percebe-se que o BCB enxerga e reconhece a importância que a cooperativa de crédito 
exerce na estratégia de inclusão financeira. Isso se dá não apenas pelo fato das cooperativas atenderem regiões menos assistidas e por sua alta capilaridade, mas também pelo fato de estar dentro dos seus princípios levar à educação financeira aos seus cooperados e comunidade. Isso faz com que a população, além de ter acesso aos serviços financeiros, saiba utilizá-los de forma adequada e consciente, ou seja, com qualidade. Diante disso que o BCB procura estar sempre presente nos fóruns sobre cooperativismo e também mantém as cooperativas de crédito sempre presentes em seus fóruns que tratam da inclusão financeira, não apenas como ouvinte, mas com participação bastante ativa por meio de palestras, apresentação do desempenho das cooperativas e sua forma de agir no projeto de inclusão financeira para as demais instituições.

As cooperativas entendem que estão cumprindo com o seu papel na Política de Inclusão Financeira, levando serviços e produtos financeiros para os seus associados a preços justos e desenvolvendo as comunidades onde estão inseridas. De acordo com o Relatório de Inclusão Financeira, a participação delas no Sistema Financeiro Nacional ainda é baixa, totalizam 2,88\% do total de ativos, no entanto, em número de instituições, as Cooperativas de Crédito ocupam o 1o lugar no ranking, com 82,33\% das instituições do Sistema Financeiro Nacional (BCB, 2015). Nas pequenas cidades brasileiras a participação delas é muito alta, sendo que, em muitas delas, a cooperativa é a única instituição financeira presente, e esse é um fator fundamental para a inclusão financeira.

Assim, os atores entrevistados mostram ter interesses comuns perante a política de inclusão financeira. As cooperativas, por ocuparem grande espaço na bancarização, justamente por ter a capacidade de abrir postos de atendimento a partir de outras variáveis que não sejam somente a questão risco e retorno, e o $\mathrm{BCB}$, com o interesse em manter o sistema financeiro saudável e eficiente, auxiliam o crescimento das cooperativas através de medidas e regulamentações que proporcionam a solidez e o fortalecimento do setor. Com isso estabelecem, como dito por todos os entrevistados, uma relação de parceria perante a política, pois, embora o BCB desenvolva o sistema, regulamentando e supervisionando, as cooperativas continuam com sua autonomia para atuar e com seu processo de governança para tomar suas decisões sem interferência política. Esse processo de parceria e interação entre os atores resultam do conjunto de ações e decisões estruturadas, no intuído de solucionar um problema considerado público, como colocado por Subirats et al. (2012) e Knoepfel et al. (2007).

Embora haja um interesse por parte de todos os atores entrevistados voltados à inclusão financeira, pôde ser percebido que o interesse nessa política por parte das cooperativas de crédito se apresenta em nível relativamente maior do que dos demais atores. As cooperativas de crédito desenvolvem ações para a inclusão financeira desde sua existência, ou seja, muito antes do BCB promover discussões sobre o assunto. Faz parte dos princípios cooperativistas a inclusão da população nos locais onde atuam e mesmo sem a presença do BCB voltada para esse tema elas continuariam exercendo essa função social, pois esse é o nicho de mercado das cooperativas de crédito. Cabe ressaltar que a inclusão financeira não é o único propósito das cooperativas de crédito. Assim como os bancos tradicionais, elas proporcionam créditos voltados ao consumo e, muitas vezes, podem ser uma opção propícia ao endividamento da população, principalmente de baixa renda, caso não proporcionem também orientações e educação financeira.

Nesse sentido é conflituoso afirmar que a política de inclusão financeira é coordenada pelo $\mathrm{BCB}$ e que as cooperativas são instituições implementadoras. Pode-se dizer que elas também estão presentes no processo de formulação, juntamente com o BCB e demais instituições, atuando de acordo com a perspectiva da abordagem multicêntrica, que considera a atuação de atores não governamentais no estabelecimento de políticas públicas (SECCHI, 2014). Indo, assim, além das interações ocorridas apenas na fase de implementação, colocadas por Souza (2003) e Hill (2006). 


\subsection{Os Recursos}

No que diz respeito aos recursos, os atores do segmento cooperativista de crédito não mantêm relações tão fortes com o BCB. O BCB autoriza o funcionamento das cooperativas de crédito quando demandado, assim como a sua expansão, mas atuar em regiões desassistidas ou carentes de serviços financeiros é uma decisão que parte das cooperativas, como mencionado por AGıc e AGıd. Portanto, não existe incentivo financeiro para isso, ou seja, os recursos patrimoniais pertencem integralmente às cooperativas de crédito. $O$ que existe é uma exposição sobre o mapeamento das regiões e um processo de reflexão, no entanto, as cooperativas não são induzidas pelo $\mathrm{BCB}$ a ocuparem essas regiões (AGıc). Assim, com relação aos recursos patrimoniais, o BCB incentiva de forma reflexiva as cooperativas a abrirem unidades em locais menos favorecidos ou fora dos centros urbanos, no entanto, muitas vezes, as cooperativas não atuam em determinados lugares por não ser viável e, por isso, não recebem autorização para funcionamento do BCB. Diante da importância da bancarização da população, o governo poderia oferecem mais incentivos para isso, como a isenção de imposto territorial ou disponibilização de um espaço público para instalação, podendo assim viabilizar a abertura de cooperativas nessas localidades.

Quanto aos recursos econômicos, as relações são estabelecidas com o BNDES e com a Sead. De acordo com AG4b, a Sead, junto com o Ministério da Fazenda, discute constantemente com as cooperativas de crédito os recursos envolvidos no Plano Safra (Plano que direciona os recursos para a Agricultura no país) e, principalmente, sobre o PRONAF (Programa Nacional da Agricultura Familiar), programa que direciona recursos especificamente para os agricultores familiares, sendo as cooperativas as principais repassadoras desses recursos. Nos fóruns do PRONAF que acontecem anualmente, conforme citado por AG2, são discutidas e acertadas as normas e as formas de remunerações do programa. Assim, quando o plano safra é lançado, essa questão já foi bastante debatida e existe um consenso entre as partes. O BNDES é o grande repassador de recursos das diversas linhas de produtos, dentre os quais os voltados ao microcrédito. Segundo o AG2, existe um departamento dentro do BNDES exclusivo para acompanhar as operações do microcrédito produtivo orientado, que monitora as operações, verificando se está dentro das regras do programa e se os recursos estão sendo aplicados na finalidade proposta. Então as relações estabelecidas estão mais voltadas para o acompanhamento e fiscalização das operações. No entanto, tanto as cooperativas entrevistadas como o próprio representante do BNDES relataram que existe troca de informações entre eles e liberdade para manifestações e exposição de ideias, assim como negociações de taxas e remunerações relacionadas a outras linhas de repasse, uma vez que as do PNMPO já são préestabelecidas nas regras do programa. Desta forma, no que diz respeito aos recursos econômicos, as cooperativas se contentam apenas em ter recursos subsidiados para repassar aos seus associados e recebem uma pequena remuneração para cobrir os custos operacionais de repassar esses recursos. No entanto, elas assumem todos os riscos que envolvem essas operações de crédito, inclusive a inadimplência é assumida pelas cooperativas, de acordo com os entrevistados $A C_{1 a}$ e $A C_{1} b$. $O$ governo não tem risco nenhum ao repassar recursos por meio das cooperativas e, portanto, poderia remunerar melhor essas instituições por essas operações.

Com relação aos recursos humanos esses são totalmente desenvolvidos pelas cooperativas de crédito, não havendo interferência de atores governamentais. As cooperativas são responsáveis por todo o processo de contratação, cargos, salários e capacitação dos seus funcionários. Segundo $\mathrm{AG}_{4} \mathrm{~b}$, a SEAD oferece apenas orientações para que os gerentes técnicos das cooperativas possam atuar com o PRONAF. As orientações são em termos de conteúdo, objetivo e normas do programa e ocorrem durante os fóruns do PRONAF. Com o MTPS não foi identificada nenhuma relação com as cooperativas de crédito que envolva recursos. $\mathrm{O}$ ministério, uma vez que cadastra as instituições habilitadas a operar o PNMPO, realiza o monitoramento e avaliação do programa, bem como elabora relatórios com base nas informações repassadas pelas próprias instituições credenciadas, como relatado por $\mathrm{AG}_{3}$. Assim, como a inclusão financeira inclui programas governamentais, como o PNMPO e o PRONAF, por exemplo, poderia existir uma maior proximidade nesse quesito, incluindo projetos que permitissem a capacitação para operacionalização dos programas por parte das 
instituições financeiras. De acordo com os representantes das cooperativas ( $A C_{1} b, A C_{2} a$ e $\left.A C_{3} b\right)$ elas não possuem a figura do agente de crédito para operar o PNMPO, o que é um aspecto importante perante o programa, fazendo parte do seu regramento. Alegam que, por manter uma grande proximidade com os associados, o gerente de crédito exerce esse papel. No entanto, as cooperativas têm aumentado significativamente o número de associados, a partir da lei de livre admissão, e essa proximidade tende a diminuir (como menciona o entrevistado $\mathrm{AC}_{3} \mathrm{a}$ ), o que torna ainda mais importante a presença de um agente de crédito, específico para essa função.

Quanto aos recursos de informações (cognitivos), tanto o BCB como o MTPS, a SEAD e o BNDES, possuem uma concentração maior de dados e informações sobre a inclusão financeira e sobre as cooperativas de crédito. Embora divulguem relatórios, são órgãos que coordenam, regulam e controlam e, portanto, podem ter privilégios de informações. Quanto aos recursos relacionais, embora desenvolvam ações coordenadas, as cooperativas de crédito são autônomas e praticam a inclusão financeira por seus próprios princípios cooperativistas. Pôde-se perceber que as cooperativas de crédito participam dos fóruns do $\mathrm{BCB}$ não apenas como ouvinte, mas também ministrando palestras no sentido de expor suas experiências e com isso motivar as demais instituições na prática da inclusão financeira. Assim, o BCB coordena as ações de inclusão financeira, de forma mais ativa, com as demais instituições, como os bancos e as OSCIPs. Com as cooperativas mantém uma relação mais de cooperação uma vez que as cooperativas praticam por si só a inclusão financeira, por questão de mercado.

\subsection{As Regras}

Com relação às regras e normas, a política de inclusão financeira não possui uma formalização como uma política governamental, ou seja, ela se constitui como um conjunto de programas desenvolvidos por diversas instituições, com foco na solução de um problema público, seguindo a perspectiva de política pública colocada por Heidemann (2010). Nesse sentido de regramento, foi possível perceber que as interações estabelecidas entre as cooperativas de crédito e o $\mathrm{BCB}$ vieram se fortalecendo no decorrer do tempo. $\mathrm{O} \mathrm{BCB}$ adotando como prática discutir no âmbito da OCB o conteúdo e motivos de mudanças das normativas, bem como de abrir consulta pública antes de publicar por definitivo as normas e resoluções, como citado por AGıh. As cooperativas de crédito têm espaço para questionar e debater entre os pares todos os itens normativos e então encaminhar as sugestões ao BCB. O representante da OCB $\left(\mathrm{AC}_{4}\right)$ colocou que o setor cooperativista considera esse procedimento importante, pois se tornam confiantes de que a normatização será implantada com o objetivo de fortalecer o setor e proporcionar-lhes maior segurança perante o mercado.

No âmbito dos ministérios, onde são feitas as normas e regras dos programas específicos da política, também ocorre um processo de participação entre os atores envolvidos. $O$ entrevistado AG4b mencionou que a Sead, junto com o Ministério da Fazenda, "vão criando normas que facilitam a atuação das cooperativas perante o crédito rural, forma-se um conselho que se reúne periodicamente para irem discutindo os programas das aplicações de crédito". O AG5 também menciona que dialoga muito por meio dos ministérios setoriais, mas que "tem um relacionamento direto com a $\mathrm{OCB}$, que frequenta e participa dos eventos cooperativistas e que dialoga muito com as próprias cooperativas", tanto que participou com um paper no livro sobre boas práticas para o cooperativismo de crédito. $\mathrm{O} \mathrm{AG}_{3}$ também relata que as cooperativas de crédito, enquanto instituições operadoras, foram chamadas e participaram das discussões para a formatação das normas do PNMPO e todo o seu regramento. Foi possível perceber então a existência de um espaço aberto, voltado para o diálogo, discussões e negociações sobre as regras e normas que baseiam as relações entre os atores governamentais e as cooperativas de crédito, não apenas diante da política de inclusão financeira, mas também perante as normas que regulam as instituições.

Desta forma, nota-se que as cooperativas se sentem seguras por serem supervisionadas pelo $\mathrm{BCB}$, pois são orientadas a seguir os caminhos corretos do crédito e de todo sistema financeiro, 
gerando confiança e credibilidade para os seus associados. Percebe-se a existência de uma proximidade com as cooperativas de crédito, permitindo sempre a existência de diálogo e manifestações. Na política de inclusão financeira, o BCB mantém uma relação de forma incentivadora e reflexiva com as cooperativas de crédito, fazendo com que elas pensem sobre o problema público e incentivando-as a procurar formas de enfrentá-lo. O relato de três entrevistados do setor cooperativista, foram transcritos na sequencia, para demonstrar esse entendimento.

O governo age mais de forma incentivadora e reflexiva nessa política. Mas só de saber que o Banco Central, antes de autorizar, avaliou a abertura de uma agência nossa em uma pequena cidade, por exemplo, isso nos dá mais segurança. (ACıb).

A relação que se tem com o ator governamental, no caso o Banco Central, ocorre de forma mais reguladora e fiscalizadora, mas como se tem os fóruns também se pode dizer que agem de uma forma também reflexiva para que as cooperativas atuem no mercado, não é uma política que vem de cima para baixo. Se você for aos fóruns irá ver que lá a maioria é cooperativas, banco tem um e outro que aparece lá. (AC2a).

Gerar espaço, para poder aprofundar debates e fazer essas reflexões é fundamental para que inclusive a própria política melhore, ela não é estável, ela vai mudando sempre (...) eu acho que todo espaço que se gera no sentido de discutir a temática, no sentido de avaliar e reavaliar, e fazer mudanças se necessário é importante e ficaria muito sem sentido se o Banco Central criasse toda uma política lá atrás e não debatesse mais, não provocasse mais discussão sobre esse tema. (AC3a).

$\mathrm{O}$ BCB vê as cooperativas como as instituições mais capacitadas a combater a exclusão financeira pelas características que possuem de manter o foco no social e não visarem lucros. Atuam numa relação de parceria com o segmento, no qual a regulação vai sendo aprimorada, as cooperativas de crédito vão melhorando a sua governança, tendo maior relevância e credibilidade no cenário econômico e conseguindo cumprir sua função no processo de inclusão financeira. Conforme cita AGra ao dizer que diante da relevância do segmento de cooperativa de crédito, desde $2005 \mathrm{o} \mathrm{BCB}$ tem um departamento lotado primordialmente para supervisão de cooperativas de crédito, e que a evolução da regulamentação ao longo do tempo foi crescendo por um processo de aproximação múltipla. Os relatos apresentados a seguir demostram a receptividade às cooperativas de credito pelos atores governamentais.

Temos realmente uma integração muito grande e temos convidado as cooperativas de crédito ao longo do tempo nessa grande agenda que hoje nós temos de cidadania financeira, que é a fusão da inclusão financeira e a educação financeira. (AGı).

O Deorf autoriza o funcionamento, acompanha e monitora as operações e atividades, autoriza a expansão, toma medidas punitivas, mas a relação que mantém com as cooperativas é muito forte, tem uma proximidade muito grande, a gente se comunica quase que diariamente. (AGic).

(...) sempre que for necessário do ponto de vista deles nós os recebemos aqui no $\operatorname{Derop}(. .$.$) essa semana pediram uma conferência aqui para$ tratar do crédito rural, aspectos normativos, e os recebemos (...) então, temos o canal sempre aberto (...) temos muito interesse em desenvolver o sistema nacional e as cooperativas têm um papel muito importante. (AG1g). 
No Denor a gente mantém um relacionamento próximo com o segmento, principalmente via OCB. Então, quando tem a necessidade de discutir algum ponto a gente aciona via $\mathrm{OCB}$ e quando eles têm essa necessidade eles também nos acionam. (AGıh).

No que tange às regras e normas, a inclusão financeira é uma política que está em constante transformação. No entanto, pôde-se perceber a necessidade de uma formalização dessa política, introduzindo planos de ação, metas, acordos de cooperação para a implementação, com cooperativas e demais instituições, no sentido de combater de forma mais acelerada, a exclusão financeira no Brasil. Nota-se a existência de leis em determinados programas que ajudam na promoção da inclusão financeira, como o programa voltado ao microcrédito e aos correspondentes bancários. No entanto, são leis que amparam atores diversos e que não são trabalhados estrategicamente, o que mostra a necessidade de coordenação entre os diferentes atores envolvidos.

\subsection{Síntese da análise da pesquisa}

A Figura a seguir apresenta um resumo das interações observadas no decorrer da pesquisa. As interações foram consideradas como "fortes" quando observadas a existência de interesses comuns, diálogos e discussões entre os atores para a tomada de decisão ou implementação de ações. No mesmo sentido, foram consideradas "interações fracas" em situações nas quais as decisões são impostas pelo coordenador da política ou tomada sem a existência de diálogos e discussões prévias. Como mostra a figura 03, não foram observadas interações "fracas", apenas em torno dos recursos as interações foram consideradas "moderadas", pois tanto os recursos patrimoniais como os humanos são de responsabilidades unilaterais das cooperativas de crédito, não havendo interação com os atores governamentais.

Figura 03: Quadro Analítico

\begin{tabular}{|c|c|c|}
\hline Elementos de Análise & Aspectos analisados & Interações \\
\hline Conteúdo da Política & $\begin{array}{c}\text { Consciência e consenso entre os atores sobre o Problema Público, } \\
\text { Grupo-alvo e objetivos; } \\
\text { Participação das Cooperativas nas decisões; } \\
\text { Participação intensa das Cooperativas nos programas; } \\
\text { Inexistência de atos formais na política, apenas em alguns } \\
\text { programas (PNMPO, PRONAF). }\end{array}$ & Fortes \\
\hline Atores & $\begin{array}{l}\text { Valores mais fortes nas cooperativas do que nos demais atores; } \\
\text { Interesses comuns e alinhados entre os atores; } \\
\text { Alinhamento de Responsabilidade e Autonomia para atuar por } \\
\text { parte das Cooperativas }\end{array}$ & Fortes \\
\hline Recursos & $\begin{array}{c}\text { Recursos Humanos a cargo das cooperativas } \\
\text { Recursos Econômicos discutidos com BNDES e Sead } \\
\text { Troca constante de Recursos Cognitivos } \\
\text { Recursos Relacionais e de Confiança em forma de parceria } \\
\text { Recursos Patrimoniais a cargo das cooperativas. }\end{array}$ & Moderada \\
\hline Regras Institucionais & $\begin{array}{l}\text { Diálogos, discussões e negociações das Cooperativas com BCB, } \\
\text { Sead, MTPS, MF sobre as Regras e Normas formais; } \\
\text { Regras e normas informais não foram identificadas. }\end{array}$ & Fortes \\
\hline $\begin{array}{l}\text { Relações e Interações } \\
\text { Gerais na perspectiva } \\
\text { dos atores }\end{array}$ & $\begin{array}{c}\text { Autonomia e liberdade de atuação das Cooperativas; } \\
\text { Relações informais e não hierárquicas; } \\
\text { Cooperação, Consenso e Parceria perante a política; } \\
\text { Inexistência de Fortes Conflitos; } \\
\text { Reflexões e fortes laços interinstitucionais; } \\
\text { Otimo desempenho das cooperativas na política; } \\
\text { Complexas interações organizacionais. }\end{array}$ & Fortes \\
\hline
\end{tabular}

Fonte: Elaborado pelo autor (2018) 
De forma geral, pode-se perceber que os atores entrevistados, governamentais e cooperativistas de crédito, possuem seus objetivos, motivações e interesses e participam da política de inclusão financeira por suas próprias razões, como apontado por Hjern e Porter (1993, apud ROCHA, 2012) ao mencionar que a participação de atores privados na política pública é intensificada de acordo com o alinhamento dos objetivos da política aos interesses próprios. Assim, é mantido um processo de interação e negociação entre os atores em prol do objetivo da política, pois atingir o objetivo da política significa atingir os objetivos das próprias cooperativas de crédito. Eles, seguindo o que coloca Kiviniemi (1985, apud Viana, 1996), interagem com ideias, valores, interesses, recursos e ações próprios, no entanto, reconhecem a relevância do problema e dos resultados almejados enquanto solução dos mesmos. Como possuem autonomia e liberdade de atuação, trabalham em uma relação de cooperação e parceria para promover a inclusão financeira, que é motivada pela reflexão promovida nos fóruns do $\mathrm{BCB}$, nos quais as cooperativas são as instituições que mais se fazem presentes, ajudando, inclusive, a incentivar as demais instituições financeiras nesse processo de implementação. Como ressaltaram os entrevistados, conflitos existem e sempre existirão, no entanto, o diálogo e a discussão ajudam a encontrar a melhor solução para o problema.

Dentro desse contexto, pode-se dizer então que as relações estabelecidas entre os atores entrevistados são influenciadas pelo conteúdo da política, pelos valores, ideias e interesses que esses atores possuem sobre inclusão financeira, pela mobilização de recursos entre esses atores, fazendo com que se alcance a sua finalidade, bem como pelo regramento que normatizam as cooperativas de crédito e os programas dos quais participam. As cooperativas de crédito mantém fortes relações com os entes governamentais perante a política de inclusão financeira, no entanto, não é essa relação que faz com que as cooperativas busquem a inclusão, mas sim os seus próprios princípios cooperativistas.

Diante de todo o exposto, a implementação da política de inclusão financeira foi estudada aqui como um processo dinâmico, que envolve complexas interações organizacionais, cuja análise dessas interações nos leva a questões sobre negociações entre atores, públicos e privados, que são quase autônomos, como colocado por Hill (2006). Devido à autonomia das cooperativas de crédito enquanto instituições financeiras, elas mantêm uma relação com os demais órgãos governamentais que envolvem constante negociação na busca do aprimoramento de suas capacidades organizacionais. Desse modo, a política de inclusão financeira, quando analisada pelas relações entre as cooperativas de crédito e os atores governamentais, se encaixa dentre as argumentações da abordagem multicêntrica discutida por Secchi (2014), ou seja, o foco dessa política pública está direcionado na busca da resolução de um problema público, sendo secundário o fato de ter como protagonista da ação um ente estatal ou não.

\section{Considerações finais}

Ao longo desta pesquisa, buscou-se olhar para a implementação enquanto um processo dinâmico de interações entre atores implementadores e atores coordenadores e/ou formuladores da política pública. A justificativa da escolha desse tema consiste na importância em buscar compreender como se dão as interações entre cooperativas de crédito, enquanto atores não estatais atuando na implementação, e agentes governamentais, enquanto atores coordenadores, na Política de Inclusão Financeira, vista a complexidade das relações que poderiam surgir nesse ambiente de diversos atores. Como elementos de análise, foram considerados o conteúdo da política, os atores com seus valores e interesses, os recursos e as regras que os envolvem na política.

Com relação ao conteúdo da política, primeiro elemento de análise, pôde-se perceber que influencia diretamente as relações estabelecidas entre os atores, pois existe um consenso entre eles sobre o problema público a ser enfrentado, sobre o grupo-objetivo e sobre as formas possíveis de intervenções. Pôde-se perceber a inexistência de atos formais para a implementação, mas sim uma atuação em forma de parceria, motivando a promoção da inclusão financeira por meio de reflexões e debates constantes. Os valores, ideias, interesses e responsabilidades dos atores entrevistados, 
segundo elemento de análise, também influenciam de forma direta nas suas relações. Tanto as cooperativas como os atores governamentais entrevistados reconhecem o papel e a importância das cooperativas para a inclusão financeira, diante da capacidade e interesse que elas têm de levarem seus serviços e a educação financeira a lugares menos assistidos, pelos seus valores e princípios cooperativistas.

Quanto aos recursos, terceiro elemento de análise, alguns pontos podem influenciar as relações entre os entrevistados fortemente e outros não muito. Os recursos humanos e patrimoniais são totalmente de responsabilidade das cooperativas de crédito, não havendo intervenção dos atores governamentais. Nos recursos econômicos, um ponto que envolve negociação é sobre a remuneração para as cooperativas poderem operar os programas e cobrir seus custos, uma vez que as taxas de juros praticadas nos programas já são pré-estabelecidas pelos ministérios setoriais que coordenam os programas. Já os recursos cognitivos e de confiança influenciam fortemente as relações entre os entrevistados, pois, embora os atores governamentais detenham níveis maiores de informações, a estrutura organizacional existente permite que elas sejam trocadas de forma constante entre os atores.

No que diz respeito às regras institucionais, quarto elemento de análise, foi possível perceber a existência de forte influência nas interações, principalmente das cooperativas de crédito com BCB. $\mathrm{O} B C B$ vem acatando muitas das demandas das cooperativas no sentido de fortalecer o segmento por meio das normativas, e vem adotando a prática da consulta pública, buscando debater previamente as mudanças com o setor, o que gera confiança e segurança para o segmento cooperativista perante $o$ mercado.

Diante do exposto, pôde-se concluir que existem autonomia e liberdade de atuação por parte das cooperativas de crédito, e que os atores entrevistados mantêm relações informais e não hierárquicas perante a política de inclusão financeira. Nessa política, o Estado (por meio do BCB e dos ministérios) e a sociedade (por meio das cooperativas de crédito) se articulam em esquemas espontâneos e horizontais para a solução de problemas públicos, da mesma forma que menciona a abordagem multicêntrica (SECCHI, 2014). As interações estabelecidas realçam a cooperação e parceria, principalmente entre as cooperativas de crédito e o $\mathrm{BCB}$, que, diante do consenso sobre a importância do tema, atuam para a reflexão em prol da inclusão financeira.

Assim, este estudo manteve a perspectiva proposta por Subirats et al. (2012), se concentrando sobre os atores, as instituições e suas interações, pressupondo que o processo de negociação e decisão mantém-se durante a fase de implementação. Pelo fato de ser uma política inacabada e estar em constante transformação, a forte atuação das cooperativas enquanto atores implementadores e a participação intensa nas discussões e nos processos de decisões que envolvem a política provocam efeitos de baixo para cima causando impacto e influenciando a formulação inicial da política pública.

Porém, o trabalho abre espaço para estudos futuros que podem ser realizados de forma mais específica, focando menos elementos ou analisando a percepção de outros atores, tanto do setor cooperativista como governamentais. Da mesma forma, estudos mais amplos também podem ser realizados, como um estudo comparativo das relações estabelecidas entre o BCB e outras instituições financeiras implementadoras. Assim, vários outros estudos podem surgir a partir desse trabalho, e podem contribuir para o aprimoramento da política de inclusão financeira, uma vez que essa política está em constante transformação, em busca da redução da exclusão financeira no Brasil.

\section{Referências}

ABREU, Kate Dayana Rodrigues de. A implementação do programa nacional de alimentação escolar (PNAE) em municípios de pequeno porte: implicações práticas e teóricas. 2014. Dissertação (Mestrado)- Fundação Getúlio Vargas, São Paulo, 2014. 
ANDRADE, Marcelo Machado Teixeira; DINIZ, Eduardo H. Articulação política na avaliação da inclusão financeira promovida pelo banco central do Brasil. O\&S, Salvador. V. 23, N. 76, p. 150-171, Jan./Mar. 2016.

AZEREDO, Thiago Botelho; LUIZA, Vera Lúcia; BAPTISTA, Tatiana Wargas de Faria. Políticas públicas e avaliação de implementação. BIB (Revista Brasileira de Informação Bibliográfica em Ciências Sociais), São Paulo, № 74, 2º semestre de 2012, jul. 2014, p.7-25.

BANCO CENTRAL DO BRASIL. Inclusão financeira. In: Fórum Banco Central sobre Inclusão Financeira, 1., Salvador. Anais... Salvador-BA, 2009.

BANCO CENTRAL DO BRASIL. Inclusão financeira. Fórum Banco Central sobre Inclusão Financeira, 1., Brasília. Anais... Brasília-DF, 2010.

BANCO CENTRAL DO BRASIL. Parceria Nacional para Inclusão Financeira. Plano de Ação para Fortalecimento do Ambiente Institucional. Maio 2012.

BANCO CENTRAL DO BRASIL. Relatório de inclusão financeira. N. 3. Brasília: Banco Central do Brasil, 2015.

BANCO CENTRAL DO BRASIL. Relatório de Cidadania Financeira. Brasília: Banco Central do Brasil, 2018.

BECK, Thorsten. Microfinance - A Critical Literature Survey. IEG Working Paper 2015/4. World Bank Group, 2015.

CACCIAMALI, Maria Cristina; CHAHAD, José Paulo Zeetano; TATEI, Fábio. Microfinanças e Política Pública na América Latina. Cadernos ROLAM/USP, Ano 8. Vol. 1. 20o8, p. 149-172.

CRAVEIRO, Silvia da Silva. Desigualdades na rede de creches conveniadas da Prefeitura de São Paulo: Um olhar a partir da teoria de implementação de políticas públicas. São Paulo: Fundação Getúlio Vargas, 2015.

FREY, Klaus. Políticas públicas: um debate conceitual e reflexões referentes à prática da análise de políticas públicas no Brasil. Planejamento e políticas públicas, Brasília-DF, n. 21, jun. 2000.

GIL, Antônio Carlos. Métodos e técnicas de pesquisa social. 6. ed. São Paulo: Atlas, 2008.

HELMS, Brigit. Access for all: building inclusive financial systems. Consultative Group to Assist the Poor (CGAP), New York: 2006.

HEIDEMANN, Francisco G. Do sonho do progresso às políticas de desenvolvimento. In: HEIDEMANN, Francisco G.; SALM, José F. (Org.). Políticas Públicas e Desenvolvimento: bases epistemológicas e modelos de análise. 2.ed. Editora Universidade de Brasília, 2010. cap. 1, p. 23-40.

HILL, Michael. Implementação: uma visão geral. In: SARAVIA, Enrique; FERRAREZI, Elisabete. Políticas públicas: coletânea. Brasília: ENAP, 2006. v.2.

KINGDON, John W. Juntando as coisas. In: SARAVIA, Enrique; FERRAREZI, Elisabete (Orgs.). Políticas públicas: coletânea. Brasília: ENAP, 2006, v. 1.

KNOEPFEL, Peter; LARRUE, Corinne; VARONE, Frédéric; HINOJOSA, Miriam. Hacia un modelo de análisis de políticas públicas operativo. Un enfoque basado en los actores, sus recursos y las instituciones. Ciencia Política, n. 3 Enero-Junio 2007, ISSN 1909-230x, págs. 6-29. 
PROCOPIUCK, Mario. Políticas públicas e fundamentos da administração pública: análise e avaliação, governança e redes de políticas, administração judiciária. São Paulo: Atlas, 2013.

ROCHA, Ana Angélica Bezerra de Melo. A importância da implementação para a análise das políticas públicas. Revista Pensamento \& Realidade. Ano XV - v. 27 nº 1/2012.

SECCHI, Leonardo. Políticas Públicas: conceitos, esquemas de análises, casos práticos. 2. ed. São Paulo: Cengage Learning, 2014.

SOARES, M.; MELO SOBRINHO, A. Microfinanças - o papel do Banco Central do Brasil e a importância do cooperativismo de crédito. 2. ed., Brasília, Banco Central do Brasil, 2008.

SOUZA, Celina. Estado do campo da pesquisa em políticas públicas no Brasil. Revista Brasileira de Ciências Sociais, 2003.18, (51): 15-20.

SOUZA, Celina. Políticas públicas: uma revisão da literatura. Sociologias, ano 8, n. 16, jul./dez. 2006, Porto Alegre, p. 20-45.

SUBIRATS, Joan; KNOEPFEL, Peter; LARRUE, Corinne; VARONE, Frédéric. Análisis y gestión de políticas públicas. 2. ed., Barcelona: Editorial Planeta, 2012.

VAN MAANEN, John. Reclaiming Qualitative Methods for Organizational Research: A Preface. Administrative Science Quarterly, 24: 520-524; 1979.

VIANA, Ana Luiza. Abordagens metodológicas em políticas públicas. Revista de Administração Pública, V. 30, n. 2, p. 5-43, mar./abr. 1996. 